\title{
The vulnerable adult experiment: Situating vulnerability in adult safeguarding law and policy
}

DOI:

10.1016/j.ijp.2017.05.011

\section{Document Version}

Accepted author manuscript

Link to publication record in Manchester Research Explorer

\section{Citation for published version (APA):}

Keywood, K. (2017). The vulnerable adult experiment: Situating vulnerability in adult safeguarding law and policy. International Journal of Law and Psychiatry, 53. https://doi.org/10.1016/j.ijlp.2017.05.011

\section{Published in:}

International Journal of Law and Psychiatry

\section{Citing this paper}

Please note that where the full-text provided on Manchester Research Explorer is the Author Accepted Manuscript or Proof version this may differ from the final Published version. If citing, it is advised that you check and use the publisher's definitive version.

\section{General rights}

Copyright and moral rights for the publications made accessible in the Research Explorer are retained by the authors and/or other copyright owners and it is a condition of accessing publications that users recognise and abide by the legal requirements associated with these rights.

\section{Takedown policy}

If you believe that this document breaches copyright please refer to the University of Manchester's Takedown Procedures [http://man.ac.uk/04Y6Bo] or contact uml.scholarlycommunications@manchester.ac.uk providing relevant details, so we can investigate your claim.

\section{OPEN ACCESS}




\title{
The vulnerable adult experiment: Situating vulnerability in adult safeguarding law and policy ${ }^{*}$
}

Kirsty Keywood, University of Manchester, United Kingdom

Forthcoming (2017) Int J Law \& Psychiatry

\begin{abstract}
This article explores the intersection of English adult protection law and policy as it impacted on the lives of people with mental disabilities. It evaluates developments that were premised on the notion of the 'vulnerable adult', in light of recent theoretical interrogation of vulnerability and the normative shifts in law and policy advocated by the UNCRPD. I argue that the policy and legal conceptions of vulnerability developed in England and Wales, if reworked, have the potential to transform our understanding of what it is to be vulnerable into a more radical and socially-grounded framework for adult safeguarding. This article concludes with some reflections on what further conceptual and policy work must be done in order to effect that transformation.
\end{abstract}

\section{Keywords}

Vulnerability; Abuse; Neglect; Safeguarding: Adult protection; Mental disability

\section{Introduction}

The abuse and neglect of adults with mental disabilities in England and Wales has a long history. Surprisingly, however, the regulatory tools to combat abuse has remained largely unchanged until the mid- twentieth century; focusing on registration, inspection, monitoring, 
reporting and prosecution of ill-treatment of people looked after outside the family home. ${ }^{1}$ It is a matter of speculation whether regulatory failure was in part responsible for the institutional care scandals of the latter part of the $20^{\text {th }}$ century, but their occurrence heralded a return to the traditional methods of regulatory control. ${ }^{2}$ Further reform was considered following the death of Beverley Lewis, a deafblind woman who had a learning disability who had died in conditions of squalor while in the care of her mother. The Health Secretary, Stephen Dorrell, indicated that he would refer to the Law Commission the question of whether new powers were needed to combat the incidence of abuse experienced by people with mental health problems and learning disabilities (HC Deb 26 July 1990 vol 177 cc431$2 \mathrm{~W})$. In response, and following lengthy public consultation, the Law Commission proposed a series of reforms to address the failings in adult protection to sit alongside its proposals on mental incapacity. ${ }^{3}$ These powers and duties would apply in respect of a vulnerable adult who was suffering or likely to suffer significant harm or serious exploitation.

Rejecting the need for law reform, the Government stated its intention to develop a safeguarding policy for England and Wales, with a view to making better use of existing legal

\footnotetext{
* This paper forms part of a special edition of the International Journal of Law and Psychiatry devoted to Article 16 of the Convention on the Rights of Persons with Disabilities. For a full view of the contents of this special edition, go to http://www.journals.elsevier.com/international-journal-of-law-and-psychiatry/. My thanks to Laura Pritchard-Jones, Paul Skowron and the anonymous reviewers for their helpful advice and suggestions. Any errors are, of course, my own. This article is dedicated to the memory of Connor Sparrowhawk and to his family.

\begin{abstract}
${ }^{1}$ Allegations of abuse were typically uncovered by those charged with the responsibility to identify and record those described as lunatics' (see, e.g. Madhouses Act 1774; Lunacy Act 1845), 'idiots' (Idiots Act 1886) and the 'feeble-minded' (Mental Deficiency Act 1913 s.25). Judicial bodies too would occasionally be alerted to the ill-treatment, whether through the exercise of powers under Chancery law to manage the property of individuals suffering from lunacy (Lunacy Act 1890; Suzuki, 1999: 126), or through their power to authorise confinement in private madhouses, licenced premises or asylums. There is voluminous literature on the institutional 'care scandals' that took place during the eighteenth and nineteenth century, in large part because inspection reports were publicly recorded and the subject of frequent discussion and debate in Parliament. Documented instances of neglect in the family home during the same period are few, although it has been noted that instances of abuse and neglect at home are referred to in political discourse that supported the development of asylum provision (Melling, Forsythe and Adair, 1999).
\end{abstract}

\footnotetext{
2 That regulatory apparatus was largely dismantled with the advent of the Mental Treatment Act 1930; as the person of unsound mind was recast as 'mental patient', with the hospital as a locus of care and support when community or outpatient support was not appropriate. Health professionals and their professional organisations expressed resistance to the notion of regulation and inspection of care standards when hospitals fell under the central governance of the National Health Service (Bevan, 2008, 87)). The classificatory and supervisory functions of the Board of Control were abolished by the Mental Health Act 1959 (s.2) and hospital inspections were performed at will by Regional Hospital Boards. The Inquiry into the abuse at Ely Hospital (Cmnd. 3975) prompted the creation of the Hospital Advisory Service, whose role was to undertake periodic inspection of hospitals (HL deb 27 March 1969 vol 300 cc1357-1490). Subsequently, the publication of the Longcare Inquiry report (Buckinghamshire Council, 1998) was reported to have "strongly influenced" (Pring, 2011, 302) the passing of the Care Standards Act 2000 (HC Deb 2 June 1997 vol 295 cc1314 -1728; HL Deb 28 March 2000 vol $611 \mathrm{cc}$ 774). The Act created a national framework for hospital and regulated services inspection and the compulsory registration of professionals seeking to work with vulnerable adults.
}

\footnotetext{
${ }^{3}$ These included a statutory duty to investigate suspected abuse (Law Comm 231, 9.16); the creation of judicial powers to authorise the assessment or placement of a person in protective accommodation; (Law Comm 231, $9.19,9.24,9.28)$ and the creation of a criminal offence of obstruction for third parties who hinder the operation of these new powers (Law Comm 231, 9.36).
} 
powers and establishing coherent processes to investigate and address allegations of abuse and neglect $(\mathrm{Cm} 44654,8.6)$. Significantly, however, the policy drew on the Law Commission's concept of the vulnerable adult as the conceptual basis for this policy (Department of Health, 2000; Welsh Assembly, 2000). Some years later, the concept of the vulnerable adult received further endorsement in the High Court's expansion of its inherent jurisdiction. That jurisdiction broadened the range of legal powers that could be utilised by the Court to safeguard individuals against the abusive influence of others ( $\operatorname{Re} S A$ [2005]).

At around the same time, academic scholarship renewed its theoretical interest in the concept of vulnerability. Vulnerability has emerged as a significant theoretical lens through which we might reframe ethico-legal relations (MacKenzie, Rogers \& Dodds, 2014; ten Have, 2016); and re-examine the basis of state obligations to secure equality (Fineman and Grear, 2013). Its emergence in legal, philosophical and bioethical literature stems from a dissatisfaction with dominant liberal formulations of the individual (e.g. MacKenzie, 2014; Anderson, 2014). This dissatisfaction is wide-ranging and embraces discontent with its failure to acknowledge the embodied subject (e.g. Grear, 2013) or the structural inequalities that generate political disadvantage and social exclusion for a range of populations who are prevented from enjoying legal and political agency on equal terms (e.g. Fineman, 2008; 2013a, 2013b); others have criticised the liberal legal subject for its failure to conceptualise not only our relation to the broader societal structures and organising ideology, but also our relation to and interdependence on one another (e.g. Herring, 2016). Such a perspective yields an appraisal of agency and obligation in the material contexts in which people live, mindful of the impacts that broader social arrangements have on these. Given the legal and policy focus on vulnerability in England and Wales at that time, vulnerability scholarship offers an important vantage point from which to examine the conceptual coherence of adult safeguarding and the operational implications of this.

This article reflects on the success of the concept of the vulnerable adult as the basis of adult protection law and policy in England and Wales. In addition, it considers the potential of the theoretical work on vulnerability to have practical and normative purchase in the lives of people who are at risk of abuse, coercion and exploitation. I suggest that the conceptual linkage of impairment and vulnerability advocated by safeguarding policy was highly problematic, since both adhere to a model of vulnerability which is firmly anchored to notions of bodily and psychological deficit that fail to account for the broader structural factors that render us vulnerable. In reviewing the unsatisfactory efforts of mental health and mental incapacity law to act as safeguarding tools, I assess the impact of the High Court's 'vulnerable adults' jurisdiction. Despite some initial concerns that the judicially conceived notion of the vulnerable adult would be subject to the same conceptual flaws as safeguarding policy, case law can be read as promoting an altogether more robust and convincing account of vulnerability. I argue that the model of vulnerability suggested by more recent English legal developments, has the potential to transform our understanding of what it is to be vulnerable into a more radical and socially grounded-framework for adult safeguarding. Importantly, these developments also offer a way forward that is consistent with State 
obligations under the UNCRPD. I conclude with some reflections on what conceptual and policy work must be done in order to effect that transformation.

\section{The dawn of the vulnerability experiment}

English and Welsh Adult protection policy (Department of Health, 2000; Welsh Assembly, 2000) claimed as its goals the prevention of abuse and the investigation of allegations of abuse. It adopted the Law Commission's gateway concept of the vulnerable adult, save that it set the age threshold at 18 rather than 16. A vulnerable adult was thus defined as a person "in need of community care services by reason of mental or other disability, age or illness and who is or may be unable to take care of himself or herself, or unable to protect himself or herself against significant harm or serious exploitation" (Department of Health, 2000, 2.2). In short, a person would not fall within the scope of the policy and be eligible for adult protection interventions unless they were deemed 'vulnerable' and the concept of vulnerability was inextricably to tie to a person's need for social care support because they are disabled, or ill, or elderly.

\subsection{Essentially vulnerable?}

At the heart of the policy lay a tension concerning the nature of vulnerability and its association with impairment and needs for support. Indeed, the definition of vulnerability was criticised from the outset for its adoption of a medical model of disability which identified the individual as the locus of their vulnerability (ADASS, 2005, 4). Locating a model of vulnerability to abuse within a framework of care needs arising from physical or intellectual impairment is intensely problematic for two reasons: Firstly, it has the potential to obscure the commonality of experience shared by disabled and non-disabled individuals and to assume that a person's vulnerability is an escapable facet of their impairing condition. Disability scholars have been vociferous in their criticism of viewing disability solely through the prism of 'personal care needs', since such perspectives underscore corporeal difference in the disabled body (e.g. Oliver and Barnes, 2012, 136) and that difference is in turn represented as a justification for legal or policy intervention. Second, a focus on a person's need for care as representing the source of their vulnerability hides from critical examination the diverse and distinct impacts of social organisation, theory and culture on the lives of disabled people. Disability is not a homogenous phenomenon: not all disabled people are vulnerable to the same things and in the same ways. The Cartesian foundations of the medical norm that underpins disability law and policy (Shildrick, 2002), for example, have impacted on people with mental disabilities in distinct ways (e.g. Penson, 2015; Keywood, 2002; Godley, 2001 (Penson, 2015)) that have not always been attended to by mainstream disability scholarship. Undoubtedly, academic challenges to the medical model of disability are diverse, ${ }^{4}$ though they have in common a commitment to challenging the model of

\footnotetext{
${ }^{4}$ Note for example the ongoing debate of repositioning the material body within the social model by those seeking to advance a sociology of (embodied) impairment (e.g. Coleman-Fountain and McLoughlin, 2013; Hughes and Paterson, 1997; McKenzie and MacLeod, 2012).
} 
deficiency and vulnerability that is represented as arising solely through personal need. Such perspectives are critically important in challenging contemporary models of care provision, which entrench dependency by orienting state responses to meeting a very narrow set of personal support needs rather than focusing on strategies that would increase people's empowerment beyond the rhetoric of choice that currently underpins social care policy.

Indeed the conceptual linkages between unwell-ness, disability, dependency and nonautonomy are currently so firmly embedded in legal, social and cultural discourses of disability (e.g. Clough, 2015; Leach Scully, 2014) that treating the correlation between disability and vulnerability as inevitable may prove irresistible. The effect of the vulnerable adult definition, if broader structural and environmental contributors to vulnerability remained unacknowledged, could be said to amount to a form of 'diagnostic overshadowing' whereby a person's vulnerability to abuse is perceived as resulting solely from a person's frailty or disability. It is, however, possible to resist such overshadowing. Writing on the abuse carried out at Longcare, a residential service for people with learning disabilities, Brown offers an important form of resistance through her exposure of the ideological, institutional, and personal factors that contributed to an abusive environment. She noted that the abuse of people with learning disabilities by the home owner and his colleagues "... occurred in a dynamic force field at the meeting point of unchecked male power, poorly trained and ill-supported staff, conflicts between a profits and care ethic and weak 'arms length' regulation." (Brown, 1999, 107). The exposure of that which remains hidden from mainstream accounts of vulnerability is invaluable in highlighting the ideological and operational flaws of safeguarding policy and practice. The development of such accounts of 'situational vulnerability' - one element of the typology put forward by MacKenzie, Rogers and Dodds (2014) - have rightly exposed the dynamic nature of vulnerability and laid bare the processes, ideologies and structures that have rendered people vulnerable to abuse (see, e.g. Lindsey, 2016; Hollomotz, 2011).

\subsection{Resilience, autonomy and mental disability}

An account of vulnerability which reduces an appreciation of a person's risk of abuse to the presence of an impairment means that action instigated under safeguarding procedures may provide individualised remedies to eliminate harm without addressing these broader factors. Thus, the removal of apparently 'abusive' actors from a service; or the removal of the vulnerable person from a particular environment may be seen as an effective elimination of the source of vulnerability and the risk of the abuse. In tandem, this policy framing of the vulnerable adult underscored the assumption that those who are not elderly or disabled possess sufficient resilience to overcome any threats to their wellbeing and safety. This is amply demonstrated by domestic violence law and policy - currently oriented to upholding and supporting the non-disabled person's autonomy and control (Sherwood-Johnson, 2013) - 
although it must be acknowledged that values such as resilience and autonomy are not valueneutral. ${ }^{5}$

Indeed, this very perspective was acknowledged by the High Court when it considered the nature of a local authority's obligations to a woman with cerebella ataxia who expressed a wish to seek assisted suicide in Switzerland. Hedley J, faced with the first case in which the No Secrets guidance was to be judicially examined, noted that $\mathrm{Z}$ was indeed a vulnerable adult within the guidance. He cautioned that "care must be exercised in the use of the term 'vulnerable'. In some context or other every human being is vulnerable. The term only has meaningful content in a specific context. In this case that context is physical and mental deficit" ( Re Z (an adult: capacity) 2004: [10]). In confirming that the legal duties owed to a vulnerable person with capacity who sought assisted suicide did not extend to the continuation of an injunction restraining $\mathrm{Z}$ or her supporters from leaving the country, Hedley $\mathrm{Z}$ underscores the notion that safeguarding policy is oriented to the protection of a discrete group of individuals with specific needs that require state support. In short, safeguarding support is not for all.

The perils of this approach are illustrated by The Serious Case Review into the Care and Treatment of Adult A (2011). Adult A had been tortured and murdered by Adult B and B's family. At the trial of B and his family members, it was claimed that the family had kept Adult A prisoner in their home in order to claim his benefits. Presenting with no apparent needs that would make him eligible for community care support, and despite a number of disclosures to criminal justice agencies of kidnapping and assault, no formal safeguarding enquires were initiated. It was suggested in the serious case review into Adult A's death that his accommodation within the care system and his subsequent periods of homelessness, drug misuse and criminal offending may have obscured professionals' assessment of his apparent invulnerability to harm and exploitation. He was perceived as having no physical or health impairments that warranted community care intervention. His exposure to alleged serious violence did not render him vulnerable in the eyes of the organisations that came into contact with him. His rejection of support, such as was offered, was treated as the expression of an autonomous expression of self-sufficiency "rather than the realities of chronic exhaustion, unemployment, depression, hunger, drugs, exploitation, street prostitution, street crime, and chronic health problems." (Luton Safeguarding Vulnerable Adults Board, 2011, 15). A serious commitment to attending to vulnerability would require those investigating allegations such as these to recognise the commonality of human precariousness (Knight, 2014). All of us, irrespective of our personal support needs, may find ourselves in situations

\footnotetext{
${ }^{5}$ The Department of Health policy on personalisation (2006), presents a good illustration of this process, since autonomy and well-being are represented as being secured through the service user exercising choices form a range of health and social care services offered; irrespective of the individual's needs for support in accessing these, or in seeking alterative supports that are not currently offered. Empowerment (in contrast to vulnerability) is represented in that policy as flowing from the exercise of choice and control over the services an individual receives. In line with free market, neo-liberal values, the policy presupposes that individuals will secure better services and thereby improve wellbeing (Mladenov, Owens \& Cribb, 2015). This policy goal persists despite evidence of the very significant difficulties that individuals experience in 'taking control' of their care unless they are provided with robust support (e.g. Ferguson, 2007; Spandler, 2004). Under this policy, the range of choices and the degree of control exercisable are profoundly constrained by political ideology.
} 
which render us vulnerable to harm or exploitation. The precise nature and extent of our vulnerability will inevitably be shaped by our personal circumstances and health needs; and how these needs are understood and responded to within in social and professional hierarchies will impact very significantly on our personal security. As Sherwood-Johnson has demonstrated, a woman in Scotland experiencing domestic abuse may be responded to in a wholly different manner, depending on whether or not she is disabled or 'infirm' and thereby managed within Scottish safeguarding policies and processes. The need to acknowledge and resist the damaging impact of patriarchal power on individual agency, irrespective of the presence of a mental disability, is simply not recognised as essential elements of Scottish safeguarding policy and practice (2013, 912-916).

\subsection{Vulnerability, care and dependency}

For all these very legitimate concerns about the impacts of a safeguarding policy which is so firmly anchored to a model of personal need arising from individual impairment and frailty, it must be acknowledged that there is currently a significant correlation between risk of abuse and having a personal support need. The most recent data, for example, indicates that only $18 \%$ of safeguarding referrals concern individuals with no, or unknown, support needs (NHS, 2016). Brown et al's review of safeguarding practice and policy attempts to capture a sense of multiple vulnerabilities, noting that "adults who are eligible to receive health and social services are additionally vulnerable to a range of abusive and neglectful behaviours has been consistently validated by research studies over the last ten years" (Brown et al, 1999: 10) (my emphasis). Allied to this are an array of reports and guidance which chart the heightened risks of harm to which disabled and elderly people are currently exposed. These include year-on-year increases in the recording of disability hate crime (Home Office 2016, 4). They also include investigations into multiple service failure and professional neglect resulting in the premature deaths of people with learning disabilities (HC 203-I London: The Stationery Office; Heslop et al, 2013 ), which did not, in some localities at least, result in effective investigations that might improve service user care or enable family members to be involved (Mazars, 2015). There is recognition here, then, that some people are more vulnerable than others. It may well be, of course, that professionals focus excessively on support needs resulting from individual disability or illness when making safeguarding referral, to the detriment of other social and environmental circumstances that might render someone vulnerable to abuse (e.g. Oakley et al, 2016, 176). Even so, it is hard to imagine that this alone would account for the very significant correlation between abuse and personal support need.

In addition, human rights law acknowledges that an enhanced set of obligations arise in relation to those who have additional needs resulting from impairment or frailty. In $\operatorname{Re} Z$ Hedley J noted that in relation to Article 2 ECHR "whilst the State has a special responsibility to those in its custody or ...those who lack competence, the position in relation 
to a competent person, albeit vulnerable, is different and the positive obligation to protect life "... is weaker than in such cases" ([2004], para 18). Moreover, the obligation to guard against inhuman or degrading treatment require attention to be paid to the "age and state of health of the victim" (Keenan v United Kingdom [2001], para 108) and that positive steps "should, at least, provide effective protection in particular of children and other vulnerable persons and should include reasonable steps to prevent ill-treatment of which the authorities had or ought to have had knowledge" (O’Keeffe v Ireland (2014), para 144).

At first sight, research data on abuse and European human rights law (Perroni and Timmer, 2013) would seem to endorse the assumption underpinning the safeguarding framework that there is something additionally and particularly vulnerable about people who have support needs ${ }^{6}$. It is important to remember, however, that correlations between a need for care services and risk of harm do not deny the presence of a range of causes that might underpin a person's susceptibility abuse. A person's heightened risk of harm because of the presence of mental or physical impairment does not require us to adhere to a medicalised model of disability. The point of critical departure here is to acknowledge that the sources of risks to abuse are drawn more deeply and widely than the individual self. Hollomotz's (2011) study into sexual vulnerability of women with learning disabilities serves as a useful example: she outlines a plurality of risk factors for sexual violence using an ecological model $(2011,38)$. She identifies a range of personal (inadequate attention to fostering self-determination); exosystemic (unsupportive domestic and institutional environments) and macro-systemic (unresponsive political and cultural structures) factors which increase a woman's risk of sexual harm. To acknowledge that she is presently vulnerable to abuse does not mean that she will always remain so; it rather demands that interventions are multi-systemic in order improve her security.

\section{Safeguarding, vulnerability and the limits of the law}

Adult safeguarding policy in England and Wales adopted a model of safeguarding which focused on the specific vulnerabilities of individuals generated by their innate characteristics but provided no distinct legal remedies to respond to those perceived vulnerabilities. Existing legal mechanisms were to be deployed to eliminate the risk of abuse. These ranged from recourse to the Mental Health Act 1983 to gain entry to persons believed to be mentally disordered who were believed to be experiencing ill-treatment or unable to care for herself (s.135), recourse to mental capacity law (now contained Mental Capacity Act 2005) to make 'best interests' decisions if the person at risk was unable to make a decision about residence or contact with the abuser and deployment of the criminal law on ill-treatment, offences

\footnotetext{
${ }^{6}$ An approach adopted also in Scotland. S 3(1) of the Adult Support and Protection (Scotland) Act 2007 defines adults at risk as those who "(a)are unable to safeguard their own well-being, property, rights or other interests; (b)are at risk of harm, and (c)because they are affected by disability, mental disorder, illness or physical or mental infirmity, are more vulnerable to being harmed than adults who are not so affected."
} 
against the person or homicide. Significantly, these legal interventions were premised on rather different conceptual foundations to No Secrets and In Safe Hands; the Mental Health Act adopted the gateway concept of mental disorder while the Mental Capacity Act utilised the concept of mental incapacity. Of course, safeguarding policy and mental disability law will frequently overlap; a person with a mental disorder or lacking capacity may be vulnerable in a particular context, but they are not necessarily so. Moreover, an evaluation of case law and Serious Case Reviews conducted during the operation of that policy indicate that mental health law and mental capacity law are ill-suited to addressing the array of safeguarding concerns that local authorities ought to be confronting.

Although the courts have claimed that mental capacity law has a protective function to make decisions in respect of "the weak and the vulnerable" (A Healthcare NHS Trust $v P$ and $Q$ [2015]: at [7]), it has proved limited in fulfilling a safeguarding role. To return to the care and treatment of Adult A; he had no obvious impairment or disturbance of functioning in the mind or the brain. Nor was there a belief, at time of agencies' engagement with him, that he had a mental disorder. Yet he was deprived of his liberty, prevented from making even the most basic of decisions free from the influence of his tormentors. The situation becomes more complex when we consider individuals who have some sort of impairment or disturbance of functioning, but the presence of other features in their life mean that it is truly difficult, perhaps impossible, to state with the confidence seemingly demanded by the courts as to what factors are responsible for the inability to make a decision that would keep them safe (see, e.g. Ruck-Keene, 2014; PC v York 2013 [58]). And even if the mental capacity law were capable in principle of being marshalled to assume a safeguarding role, failings in its implementation has left many people without effective protection. The serious case review into the death of Steven Hoskin identified a number of points at which interventions by adult social care, police and housing agencies could have exposed the very serious abuse he was experiencing. When Stephen told his key worker that he no longer required support, his case was closed, even though he appeared to be sharing his one-person bedsit with a number of other people, many of whom were known to the police. The review cautions that “... Steven's 'choice' should have prompted a dialogue in order to ascertain the circumstances surrounding his decision, the factors that prompted the decision to discontinue his social care support, and to consider whether a more effective working relationship with Steven could be created." (Flynn, 2007, 7.2.6). Such approaches have attracted criticism of the House of Lords Committee on the Mental Capacity Act that that the presumption of capacity laid down in the general principles to that Act have been (mis)interpreted in a number of cases to "paralysing effect", either because it has been understood as precluding the making of inquiries into whether decisions are validly made or because professionals have been concerned that their assessment of a person's decision-making ability might result in legal challenge (HL Paper 139, para 60-65).

The Mental Health Act may also be limited in what it can do to prevent the occurrence of abuse or neglect. Guardianship (s.7) is unlikely to be an option for those learning disabled individuals who are targeted by family members or local gangs - perpetrators of so-called 'mate crime' - unless their conduct can be described as seriously irresponsible. In light of the 
court's ruling in $\operatorname{Re} F$ (1999) this may be unlikely. In that case, a young woman with a learning disability was removed from the family home following allegations of multiple forms of abuse. The court ruled that her attempts to return to her neglectful and abusive family environment did not amount to "abnormally aggressive or seriously irresponsible conduct" because her desire to return home was seen as a "almost universal" urge, to which many young people succumbed $(1999,6)$. Moreover, where mental health issues coexist with substance misuse or alcohol addiction, individuals may not be considered as suitable candidates for compulsory inpatient care (e.g. South Central NHS Strategic Health Authority, 2006: para 8.10). Similarly, use of s.2 or s.3 may not be considered appropriate if detention for assessment or treatment is contemplated, because the risk presented to the service user is not considered to be sufficiently great or the benefits too meagre to warrant inpatient compulsion. (See, e.g. Flynn, 2010, para 5.5).

The application of the criminal law at this time has also offered very limited comfort. Quite apart from concerns that the offences of ill-treatment and wilful neglect meet the requirements of legal certainty (Allen, 2013; HL, 2014 para 201-309), the moral wrong that is censured by such offences is contingent on the status of the victim as having a mental disorder (Mental Health Act s.127) or believed to lack mental capacity (Mental Capacity Act s.44). A number of high profile prosecutions have been dropped because of concerns over whether the threshold of 'neglect' had been triggered. Of particular note is the controversial decision of the CPS to withdraw the prosecution of eight care workers investigated during Operation Jasmine (Flynn, 2015: 11) following the death of 63 elderly residents in privatelyowned care homes. Other prosecutions have resulted in acquittals due to technical distinctions over whether the patient was receiving physical as opposed to psychiatric treatment (Cornwall Live, 2009). In addition, operational and logistical challenges arise when allegations of abuse or neglect relate to institutional care in which there are likely to be a large number of victims and perpetrators, which may undermine the effectiveness of criminal investigation and prosecution (Flynn, 2015: 206). Moreover, the application of the offences under the MCA and MHA has meant that to date, there has been considerable disparity in prosecution practice between health and social care practitioners. Doctors, for example, have rarely been subject to prosecution for ill-treatment or wilful neglect. In a number of cases, prosecution under for ill-treatment or wilful neglect was not explored fully, even though at least in some cases the circumstances surrounding the patient's care would appear to have fallen within the scope of the MHA and MCA offences (Griffiths and Sanders, 2013).

\section{Filling the gap - the vulnerable adults jurisdiction}

The failure of the government to establish the creation of dedicated duties and powers targeted at eliminating abusive and neglectful care undoubtedly provided the judicial impetus for the development of the vulnerable adult's jurisdiction. Deriving from the exercise of inherent jurisdiction, and described by one of its chief architects as an example of "judicial law-making on an heroic scale" (Munby, 2014: 64), the High Court is now empowered to act in respect of 
adults who may fall outside mental health and mental capacity legal frameworks in circumstances where an individual is at risk of abuse, exploitation or neglect. The frequently stated goal of the courts in cases such as these and those determined under mental capacity law is not to embark on 'social engineering' (e.g. A Local Authority v Mrs A and Mr A [2010], [116]) and substitute the courts' determination of what is best, but rather to take the necessary steps to support the person to make their own decision, free from undue pressure ( $L B L v R Y J \& \mathrm{VJ}$ at [62]). To date, the jurisdiction has been triggered when what a vulnerable adult decides is believed to be undermined by coercion; either because the person's wishes are the result of coercive influence (decisional vulnerability), or because the person is unable to carry out her decisions because of this influence (executional vulnerability).

The jurisdiction's first elaboration as distinct from mental incapacity law can be traced to 2004 . In Re G (2004), Bennett J extended the scope of the High Court's jurisdiction to limit the influence of a father on the health care decision-making of his daughter. Understood by some at the time to be a 'revolving door' incapacity case (Dunn et al, 2008), it represents the first attempt of the High Court to push the frontiers of the inherent jurisdiction beyond the established application of mental incapacity principles. Such a manoeuvre was largely welcomed by commentators who had noted that autonomy had been inadequately protected by the Mental Capacity Act 2005 (e.g. Herring and Wall, 2015). It was not until a year later, however, that Justice Munby sought to elaborate the foundations of the jurisdiction more clearly when he concluded that he had authority to use the High Court's jurisdiction in order to protect a profoundly hearing-impaired young woman with a learning disability ( $\operatorname{Re} S A$ [2005]). The local authority in this case had been increasingly concerned that SA's parents were going to take her to Pakistan to have an arranged marriage. SA had very limited means of communication with her family and this, according to the Local Authority, made her particularly vulnerable. Justice Munby concluded that the inherent jurisdiction - that "great safety net" of English law (Re F [1989] per Lord Donaldson MR) - was applicable to the circumstances here and could be used to provide some protection to SA. Importantly, this jurisdiction applied to the "vulnerable adult who, even if not incapacitated by mental disorder or mental illness, is, or is reasonably believed to be, either (i) under constraint or (ii) subject to coercion or undue influence or (iii) for some other reason deprived of the capacity to make the relevant decision, or disabled from making a free choice, or incapacitated or disabled from giving or expressing a real and genuine consent (at [77]).

The jurisdiction, then, overlapped with but was distinct from existing legal mechanisms that had been used as safeguarding tools. The High Court acknowledged that far more was required of autonomy than an ability to understand, weigh and communicate information, and returned judicial focus to the question of the impact of coercion and abuse on decision making. In so doing, it offered a more robust account of autonomy than that offered by the Mental Capacity Act, the latter often safeguarding freedom rather than a notion of autonomy that is in any sense meaningful to bioethicists and philosophers (e.g. Coggon and Miola, 2011; Keywood, 2011). The jurisdiction has at its heart, the concept of the vulnerable adult. Somewhat enigmatically, Munby J. declined to offer a closed definition of who might be considered vulnerable to attract the intervention of the jurisdiction, but indicated that it would embrace "...someone who, whether 
or not mentally incapacitated, and whether or not suffering from any mental illness or mental disorder, is or may be unable to take care of him or herself, or unable to protect him or herself against significant harm or exploitation, or who is deaf, blind or dumb, or who is substantially handicapped by illness, injury or congenital deformity" (at [82]). ${ }^{7}$

Any concerns that the concept of the vulnerable adult would serve as some form of 'diagnostic threshold' for the jurisdiction were quickly dispatched by Munby J. In a somewhat surprising intellectual manoeuvre he indicated that the concept of the vulnerable adult was neither a necessary nor a sufficient condition for the exercise of the jurisdiction. This was affirmed in $R e$ $D L$ [2011] when Theis J. reiterated (at [53]) that the jurisdiction is applicable whether a person is vulnerable or not. The value of the concept, according to Munby J., is "pragmatic and evidential" ( $\operatorname{Re} S A$ [at 83]), in that 'vulnerable' adults - that is, those with the impairments and incapacities featured in his description - are more likely to be at risk constraint or coercion than those who are not. It is difficult to accept its merits or to appreciate the wisdom in establishing a jurisdiction around a concept which is deemed non-essential to its operation.

The expansion of the jurisdiction to provide protection for vulnerable adults was not met with universal praise; some expressed concern that the use of substitute decision-making in cases where a person retains mental capacity may be experienced as profoundly disempowering (e.g. Dunn, Clare and Holland , 2008); others doubted the constitutional and doctrinal correctness of extending the High Court jurisdiction (e.g. Hewson, 2013). Certainly, the ruling in SA has generated considerable difficulties for the courts in trying to articulate precisely what it is that brings a person's circumstances within the scope of the jurisdiction. This is an understandable concern in light of the courts' inelegant efforts, characterised according to Hewson as "wellmeaning, sloppy thinking" (2013: 459), to shape the jurisdiction. Of particular concern is the association drawn in the judicial imagination between vulnerability and disability. PritchardJones (2017), for example, has challenged the courts for equating disability or old age with vulnerability. In $R e S A$, Munby J's description of the young woman can be read in this light. It is noted that:

SA is plainly a vulnerable adult. She is substantially handicapped by her disabilities. And, particularly because she is deaf and dumb, she may well be unable to take care of herself and protect herself against significant harm or exploitation if placed in unfamiliar surroundings or deprived of access to those able to communicate with and for her in British Sign Language.

It is possible to discern from this, in line with Pritchard-Jones's concern, that SA is seen as a vulnerable adult by virtue simply of her disabilities. If we are to view SA as vulnerable because she is disabled, even assuming that this will not by itself justify the exercise of the inherent jurisdiction, there is concern that her 'intrinsic' vulnerability will underscore her difference from the self-determining legal subject who is able independently to adopt strategies to combat abuse and neglect. This would have a number of potential effects. Firstly, it would support an interpretation of vulnerability as an immutable characteristic that

\footnotetext{
${ }^{7}$ The archaic language in the latter part of this description refers back to s.29 the National Assistance Act 1948, which identified those who were to benefit from the state's duty to provide welfare services.
} 
is unlikely to respond to focussed attempts at empowerment or fostering resilience of the vulnerable person. Second, it would shift judicial attention onto addressing the conduct of third parties, those non-disabled actors whose conduct (in contrast to the vulnerable person) is considered amenable to management and control. In so doing, any judicial intervention fails to capture the array of influences, structures and ideologies that operate in different ways to render people more or less vulnerable, irrespective of whether they have disability. Third, the framing of the disabled person as vulnerable in contrast to the non-disabled, invulnerable person would operate as a form of 'othering' whereby bodily and cognitive difference is seen as justifying differential treatment in the eyes of the law (e.g. Keywood 2000). Of course, differential treatment is not in itself problematic, but the differential treatment that may arise here is advanced as a justification affirming and reinscribing disadvantage and disempowerment. The comparison of vulnerable people with those considered to be invulnerable is a relation of power, for as Pritchard-Jones explains (2017), the process of 'othering' presupposes a norm; a yardstick against which the moral, social and political value of others will be determined. That norm is premised on a model of liberalism which emphasises the importance of rational choice-making, excludes from consideration ideological and structural impediments to self-determination (Harrington, 1996) and which represents the paradigmatic subject of legal discourse as disembodied (Naffine, 1997). The disabled body, and indeed the disabled mind, is necessarily excluded from this norm and becomes understood as deficient; as 'lacking' those qualities that are emblematic of the empowered legal self. The disempowerment of disabled people may be seen not merely as an effect of legal power, but as deeply implicated in its formation.

Certainly, some of these effects may be observed in the courts' framing of the vulnerable adult. In $R e S A$, for example, Munby J notes that "there is every reason to believe SA may, by reason of her disabilities, and even in the absence of any undue influence or misinformation, be disabled from making a free choice and incapacitated or disabled from forming or expressing a real and genuine consent.". It is important to note, however, that any claim that SA is inherently vulnerably because of her disability is undermined by her own narrative, which presents a woman who is articulate when supported to communicate and who has clear views about marriage. For example, she was explicit that she wanted to marry a Muslim man, who would be chosen for her by her parents and would most likely come from Pakistan. However, she was adamant that she wanted to have the final decision over whether her parents' choice of husband was suitable for her and it was essential that any suitor would be able to speak English and would be willing to live in the UK with her and indeed marry in the UK (at [24]). This narrative would not, however, appear to provide the basis for the court's determinations in this case. At a time when English law is increasingly recognising the residual autonomy interests of those who lack capacity to make an autonomous decision (e.g. Wye Valley v B [2015]; Aintree v James [2013]), it is right to question whether the wishes and values of those subject to the inherent jurisdiction might, at least in some cases, seem to count for so little. Indeed, 'best interests' interventions, whether they are litigated under the Mental Capacity Act 2005 or the vulnerable adults jurisdiction, may create new, 'pathogenic' forms of vulnerability (see, e.g. Clough, 2015a, 2015b). In Re $G$, a young woman with a mental health diagnosis and currently having capacity to make 
choices about residence and contact with her father, was considered to be at significant risk of being rendered incapacitous due to the overbearing influence of her father. If the goal of the jurisdiction is to facilitate 'unencumbered decision-making' ( $L B L v R Y J$ [2010] at [62]), it is difficult to see how or why G's choices to have rather more supervised contact with her father should not have been followed, particularly since this choice was reached after receiving support from an advocate (at [49]). It is even more difficult to see how it might justify the removal of a woman with learning disabilities into protective accommodation, thereby depriving her of her liberty, in order to restrict contact with her abusive partner (see the recent obiter remarks of Parker J. in NCC v PB and TB [2014] at [121])

Perhaps more promisingly, the injunctions granted in the case of $\operatorname{Re} D L$ (2010), a case concerning the abuse and neglect by DL of his elderly parents, sought to restrict DL's abusive behaviour, but did not attempt to restrict contact or remove him from the family home. The expectations of the local authority and the court were that the family unit and the enormous emotional benefit derived from it by DL's parents, would remain intact. Although Parker J has contended that the inherent jurisdiction enhances autonomy through the removal of coercion (at 113), care must be taken to ensure that autonomy is rather more than a hollow victory. In large part, the courts would seem to be striking the right balance in declining to use the jurisdiction to restrict sexual contact with an abusive partner in cases where a person has capacity to consent to sex (LB of Ealing $v K S$ and others [2008] at [148]); or to impose an injunction restricting contact of a partner who had given undertakings to the court not to interfere with his wife's contraceptive decision making (Local Authority v A [2010]).

\subsection{Vulnerability reframed?}

Despite these concerns, there is scope for viewing the jurisdiction as having the potential to offer a more credible account of vulnerability. This would take account both of the commonality of the vulnerable experience, irrespective of disability, and the broader environmental factors that render us vulnerable. The case of $R e S A$ serves as a useful illustration here. It is possible to reinterpret this case as identifying SA's vulnerability as resulting from the environment in which she may find herself. It is the fact that, if taken to Pakistan, SA would not be able to communicate in Urdu and would therefore be isolated and unsupported, that renders her vulnerable and not her disabilities per se. Read in this light, it becomes possible to see how any of us might find ourselves vulnerable to exploitation when placed in an environment in which we cannot be understood. On this reading, then, SA's vulnerability can be understood as necessarily situational.

The courts have, on occasion, acknowledged at least some of the more immediate environmental impacts on a woman's vulnerability in the case of Local Authority $X v M M$ [2007]. In that case, Munby J. used the inherent jurisdiction to regulate contact between a woman with a mental health diagnosis (MM) and her long-term partner (KM). In that case, he saw her vulnerability as arising from an interplay between her mental disorder, her abusive relationship and her life circumstances. He described MM as a “... vulnerable woman whose physical and mental health has on numerous occasions been significantly prejudiced because 
of the lifestyle which, under KM's tutelage, guidance and direction, she has chosen to live" (at [140]). The impediments to sexual agency, experienced by MM, are not, I suggest, so radically different to those experienced by very many women who do not have disabilities. In a case decided by the Court of Protection, a woman reported that "..even if she didn't want sex she would have to go along with it as she wants to be 'lovey dovey'" (Derbyshire County Council v AC [2014] at [30]). To confine such experiences as particular to disabled people ignores the array of coercive techniques that operate to inhibit female sexual empowerment more broadly (e.g. Hayes 2014; Chung, 2005).

The commonality of oppression and coercion experienced by people who are and who are not disabled would appear to be a feature absent from the early cases brought to the High Court. Most recently, however, the High Court has avoided recourse to Munby J.'s description of the vulnerable adult (Re SO [2015]; Amina Al-Jeffery v Mohammed Al-Jefferey [2016]). Amina Al-Jaffrey was brought up in the United Kingdom until, at the age of almost 17, she moved to Saudi Arabia to live with her father. Amina had no particular health or social care needs that demanded state support or intervention. Her relationship with her father, however, had become so oppressive that she was effectively confined in her home for the next four years, unable to return to the United Kingdom. Her return to her father's home following a successful escape could not, in the eyes of the Court, be regarded as a voluntary choice since Amina believed, justifiably, that she would be imprisoned if she did not return home. Confirming the application of the jurisdiction to adults who are British citizens not currently resident in the United Kingdom, Holman J. considered the jurisdiction essential to ".. create conditions in which she, as an adult of full capacity, can exercise and implement her own independent free will and freedom of choice" (at [66]). In so doing, Holman J. made an order requiring Amina's father to facilitate his daughter's return to the United Kingdom, through the payment of her air fare and the return of her passports. Significantly, there is scope within the ruling for the Court to acknowledge the broader structural impediments to her agency, manifested in this case through the application of Sharia Law requiring her to obey her father and cultural expectations concerning her status as an unmarried woman. The Court takes seriously her concern that her liberty is compromised and that, as a young woman living in Saudi Arabia, her choices as to residence and contact would have to yield to the wishes and preferences of her father's, on pain of imprisonment if necessary (at [19]).

There are undoubtedly challenges facing the courts as to how they develop more nuanced accounts of vulnerability that do not collapse into established tropes concerning disabled and infirm people as lacking the shared human capacities for social engagement and resilience. Having a mental disability does not necessarily render one vulnerable, although inhabiting an environment that does not recognise one's entitlement to social inclusion may certainly have that effect. It is possible, then, to recognise the particular vulnerability experienced by people with personal support needs and disabilities living in contemporary society. To do so does not require us to resort to medicalised conceptions of disabled people as inherently needy and more at risk of exploitation. It is not, I think, asking too much of our legal institutions to acknowledge this. Rather, the challenge for the courts is whether, and how, to intervene. Clough (2015b), for example, has identified some promising strategies the courts might adopt 
in countering sexual vulnerability, although to date the focus in the vulnerable adults jurisdiction has to been to restrain the potential for abuse and constraint rather than providing practical steps to promote increased resilience. In an age of austerity, what support there is at present is likely to diminish further.

\section{The demise of the vulnerable adult experiment?}

A review of recent policy developments would suggest that England's vulnerable adult experiment may be coming to an end. The Care Act 2014 and the Social Services and Wellbeing (Wales) Act 2014 have replaced No Secrets and In Safe Hands. Provision of safeguarding support is now to be provided to those at risk who have "a need for care and support" (s.42 (England); s.126 (Wales)). ${ }^{8} \quad$ Lindsey is optimistic that the removal of references to disability, illness and age in the Act provides sufficient conceptual space to develop a multi-layered account of vulnerability $(2016,307)$. Certainly, the Act makes clear that being eligible to receive care (which remains dependent on the presence of a physical or mental impairment or illness (Care and Support (Eligibility Criteria) Regulations 2015)) is not a precondition to receiving safeguarding support (s. 42(1)(a); s.126 (1)(b)). Much, of course, will depend on how, if at all, this distinction is understood by those tasked with implementing the law. Given the strong association of disability with needs for care, it is a distinct possibility that there will be little shift in practice.

There is movement, too, in the High Court. Recent cases under the inherent jurisdiction are moving away from the description of the vulnerable adult developed in $R e S A$. This suggests either that the inherent jurisdiction has jettisoned the vulnerable adult gateway concept altogether, or that it has broadened its scope to acknowledge the multiple and varied sources of vulnerability. With relatively few adult protection cases coming before the High Court, it is difficult to be certain which of these possibilities is the more likely. The most recent case before the High Court would suggest the latter, in claiming that the legitimacy of legal intervention hinges on the question of whether the person at risk of abuse is indeed a vulnerable adult (Re FD [2016], 58). Similarly, the application of the inherent jurisdiction to a broader range of people does not necessarily alleviate concerns that vulnerability is represented, by some of the judge $s$ at least, as an inherent facet of the disabled self. It is noteworthy for example, that those cases involving individuals who are not disabled or elderly have proceeded on the basis that they lack apparent executional autonomy. In other words, their decisions are considered to be sufficiently well-reasoned and free from coercion but their ability to carry out those decisions is potentially compromised by the actions of third parties. It remains to be seen whether decisional vulnerability (whereby a person's choicemaking is compromised by duress or abuse) will be considered to affect those who are not elderly or disabled.

\footnotetext{
${ }^{8}$ The legislation now brings with it dedicated responsibilities to make enquiries in England (Care Act 2014 s.42) and a duty to make enquiries, mandatory reporting and a power to entry to premises in Wales: Social Services and Well-Being (Wales) Act 2015, s. 126-128)
} 
Notwithstanding these operational considerations, there is considerable merit in retaining a critical focus on vulnerability. It allows for the acknowledgment of commonality of experience between disabled and non-disabled people which contribute to the disruption of the essentialising of the disabled mind and body as intrinsically vulnerable through its deficiency. An ethics of vulnerability which takes as its starting point the materiality of all human forms and the insecurity that is generated from this necessarily requires us to reflect on whether strategies adopted to respond to this vulnerability are legitimate. In so doing, it shines a light on the neglected narratives and sources of disadvantage and neglect. In 2013 Connor Sparrowhawk, a young man with autism, drowned in a bath during an epileptic seizure in an assessment and treatment unit in the South of England. Connor's mother, speaking recently of her son's admission to the unit, observed that "that was the day he stopped being a sixth-former" (Ryan, 2016). She reminds us that it was not Connor's disabilities that rendered him vulnerable, but his placement within an institution that paid inadequate attention to his health and emotional welfare (Southern Health NHS Trust, 2016), operating against a social backdrop that treats the lives of disabled people as having lesser moral worth.

This framing of vulnerability would appear to be in line with the United Nations Convention on the Rights of Persons with Disabilities, whose emergence in international law occurred after the development of the vulnerable adult experiment in England and Wales. It meets the goal of the Convention that States to develop law and policy that is not premised on legal classifications that discriminate against disabled people. The obligation to protect disabled people from abuse and violence (Article 16),for example, seeks to recognise the specific risks to safety and wellbeing that are experienced by disabled people in modern societies but does not justify differential legal strategies that remove legal rights and privileges on grounds of disability (para 13). Moreover, the Convention calls for models of supported decisionmaking that not only accommodate the wishes, values and preferences of the disabled person, but demand that they are have normative legal force on the same terms as the decisions of non disabled people (Article 12, General Comment No. 1, 2014). Quite what sorts of models will satisfy the Article 12 obligation is a matter of ongoing debate (e.g. Flynn \& ArsteinKerslake, 2016; Dawson, 2015). Nevertheless, the fostering of self-determination with the provision of support is important in increasing personal satisfaction (Karr, 2011) and is seen as having a key role to play in fostering resilience to abuse and neglect (Hollomotz, 2011).

To acknowledge the universal vulnerability of all subjects does not require us to claim that being disabled in contemporary British society will always result in an increased risk of abuse or neglect; or that all disabled people will experience abuse in the same way. The UNCRPD Preamble explicitly acknowledges the intersecting and overlapping dynamics of oppression that impact on people's lives through "multiple or aggravated forms of discrimination on the basis of race, colour, sex, language, religion, political or other opinion, national, ethnic, indigenous or social origin, property, birth, age or other status" (Preamble, para p). 
Acknowledging the specific and varied modes of oppression that impact on the lives of disabled women, the Convention's General Comment No 3 urges a recognition that disabled women are not a homogenous group (para 5) and that State practices must be sensitive to multiple and intersectional discrimination in its monitoring of and responses to disability discrimination (para 16). Legal strategies to combat intimate abuse of women with a learning disability, for example, must acknowledge the gendered dynamics of heterosexual relationships and the impacts of adopting a strategy which is oriented at protecting her from harm at the expense of empowering her to articulate and explore what sort of relationship she would like to have.

\section{Conclusion}

It is clear that legal and policy formulations of vulnerability have largely operated within much narrower parameters than the theoretical work advanced by vulnerability theorists. Current law and policy accommodations of vulnerability have failed, in significant part, to see the broader state apparatus as complicit in producing vulnerability. They have focussed goals on remedying vulnerability as being targeted at the personal level, for example, through excluding the abuse. It is, however, possible for legal frameworks and processes to accommodate more expansive accounts of vulnerability and there are strong motivations (not least the UK's ratification of the UNCRPD) to do so. These are particularly evident in the criminal offence of controlling or coercive behaviour in an intimate or family relationship (s.76 Serious Crime Act 2015) which explicitly acknowledges the significant gendered and heteronormative dimensions to abuse (Home Office, 2015: para. 20-22). Beyond this, there is a need within the broader regulatory architecture to develop more responsive strategies to respond to people's vulnerability. Some important developments are already under way here. These seek to capture not just people's experience of feeling safe through audit (see, e.g. NHS Digital, 2016; Norrie et al 2016) and inspection (Health and Social Care Act 2008 (Regulated Activities) Regulations 2014, Reg 13; CQC, 2015), but also ensure increased participation of people in framing the goals of safeguarding intervention (Cooper et al, 2016) such that the outcomes of safeguarding are owned, to a greater degree, by the person whom they are intended to protect.

For all the work that is done 'on the inside' to transform services, outsider activism continues to be key to challenging established responses to abuse and neglect that compound and contribute further to people's disempowerment. The refusal to conform to culturally ascribed roles of dependent care recipients and grateful carers has the potential to trigger important changes in safeguarding law, policy and practice, although this is not an easy process at domestic or international level (e.g. Karr, 2011). Sara Ryan's blog profiling her son's care in an assessment and treatment unit makes explicit her transformation into 'difficult' (Ryan, 2016) and 'complaining' (Ryan, 2016) mother in the eyes of treatmentproviders and commissioners in the light of her refusal to accept the poor care meted out to her son. His supposed vulnerability to premature death was contested through her activism. Her efforts in the light of his death led to the creation of a grass roots movement which has challenged NHS determinations that her son died of natural causes and has focussed attention 
on the way unexpected deaths of people with learning disabilities are investigated and recorded (CQC, 2016) as well as prompting reflection on the need for legislation to prevent inappropriate removal of people with learning disabilities into institutional care $(\mathrm{Cm} 9007$ \& $\mathrm{Cm}$ 9142, 2015). Her rejection of dominant ascriptions of vulnerability highlights the need for a sustained interest and interrogation of what it means to be vulnerable.

\section{References}

ADASS. (2005). Safeguarding adults: a national framework of standards for good practice and outcomes in adult protection work. London: ADASS.

Allen, N. (2013). Psychiatric Care and Criminal Prosecution page numbers . In D. Griffiths \& A. Sanders, Bioethics and the Criminal Law (pp.159-173). Cambridge: CUP.

Anderson, J. (2014). Autonomy and Vulnerability Entwined. In C. MacKenzie, W. Rogers \& S. Dodds (Eds.), Vulnerability: new essays in ethics and feminist philosophy (pp .134-161). New York: OUP.

Arstein-Kerslake, A., Flynn, E. (2016). he General Comment on Article 12 of the Convention on the Rights of Persons with Disabilities: A Roadmap for Equality Before the Law. The International Journal of Human Rights, 20(4), 471-490.

Bevan, G. (2008). Changing paradigms of governance and regulation of quality of healthcare in England. Health, Risk \& Society, 10 (1), 85-101.

Brown, H. (1999). Abuse of people with learning disabilities: layers of concern and analysis. In N. Stanley., J. Manthorpe. B. Penhale. (eds) Institutional abuse: perspectives across the life course (pp. 89-109). London: Routledge.

Brown H., Kingston P. and Wilson B., Adult Protection: an overview of research and policy, Journal of Adult Protection 1(1), 1999, 6 - 16.

Buckinghamshire Council. Independent Longcare inquiry, 1998. Buckinghamshire Council; Buckinghamshire.

Care Quality Commission (2015). Statement on CQC's roles and responsibilities for safeguarding children and adults. London: CQC.

Care Quality Commission (2016). Learning, candour and accountability: A review of the way NHS trusts review and investigate the deaths of patients in England. London: CQC. 
Chung, D. (2005). Sex, Love and Abuse: Discourses on Domestic Violence and Sexual Assault. Women's Studies International Forum, 28(6), 445-455.

Clough, B. (2015a). 'People like that': realising the social model in mental capacity jurisprudence' Medical Law Review, 23(1), 53-80.

Clough, B. (2015b). Vulnerability and Capacity to Consent to Sex- Asking the Right Questions? Child and Family Law Quarterly, 36(4), 371-397

Coggon, J. \& Miola, J. ( 2011) Autonomy, liberty, and medical decision-making. Cambridge Law Journal, 70(3), 523-547.

Coleman-Fountain, E. \& McLaughlin, J. (2013). The interactions of disability and impairment. Social Theory \& Health, 11(2), 133-150.

Cooper, A., Briggs, M., Lawson, J., Hodson, B., Wilson, M. (2016). Making safeguarding personal temperature check. London: ADASS.

Cornwall Live (2009). Judge directs jury to acquit carer. http://www.cornwalllive.com/judgedirects-jury-acquit-carer/story-11439512-detail/story.html

Dunn, M., Clare I.C.H, Holland, A.J. (2008). To empower or to protect? Constructing the 'vulnerable adult' in English law and public policy. Legal Studies, 28(2), 234-253.

Flynn, M. (2007). The Murder of Steven Hoskin: A Serious Case Review (Executive Summary). Cornwall: Cornwall Adult Protection Committee.

Dawson, J. (2015). A realistic approach to assessing mental health laws' compliance with the UNCRPD. Int J Law \& Psychiatry, 40, 70-9.

Department of Health. (2000). No secrets: guidance on developing and implementing multiagency policies and procedures to protect vulnerable adults from abuse. London: Department of Health.

Department of Health. (2006). Our Health, Our Choice, Our Say. London: TSO.

Fineman, M. A. (2013a). Equality, Autonomy, and the Vulnerable Subject in Law and Politics.

Fineman, M. A. (2008). The vulnerable subject: anchoring equality in the human condition. Yale J Law \& Feminism, 20(1), 1-23.

Fineman, M. (2013b). Equality, Autonomy and the Vulnerable Subject in Law and Politics. In M. Fineman \& A. Grear (Eds.), Vulnerability: reflections on a new ethical foundation for law and politics (pp. 13-27). Farnham: Ashgate.

Fineman, M., Grear, A. (Eds). (2013). Vulnerability: Reflections on a new ethical foundation for law and politics. Farnham: Ashgate.

Flynn, M (2010) Serious case review re 'Ann'. Sheffield: Sheffield Adults Safeguarding Partnership Board. 
Flynn, M. (2015). In search of accountability: a review of the neglect of older people living in care homes investigated as Operation Jasmine. Cardiff: Welsh Assembly.

Godley, D. (2001). 'Learning difficulties', the social model of disability and impairment: challenging epistemologies. Disability \& Society, 16(2), pp. 207-231.

Griffiths, D. \& Sanders, A. (2013). Bioethics and the Criminal Law. Cambridge: CUP.

Ferguson, I. (2007). Increasing user choice or privatizing risk? The antinomies of personalization. British Journal of Social Work, 37(3), 387-403.

Harrington, J. (1996). Privileging the medical norm: liberalism, self-determination and refusal of treatment. Legal Studies, 16(3), 348-367.

Hayes, S. (2014). Sex, love and abuse: discourses on domestic violence and sexual assault. London: Palgrave McMillan.

Herring, J., Wall, J. (2015 ) Autonomy, capacity and vulnerable adults: filling the gaps in the Mental Capacity Act. Legal Studies, 35(4), 698-719

Herring, J. (2016). Health as Vulnerability; Interdependence and Relationality. The New Bioethics, 22(1), 18-32.

Heslop, P., Blair, P., Fleming, P., Hoghton, M., Marriott, A., Russ, L. (2013). Confidential Inquiry into premature deaths of people with learning disabilities (CIPOLD). Bristol: Norah Fry Research Centre.

Hewson, B. (2013). 'Neither Midwives nor rainmakers' - why D.L. is wrong. Public Law, 451-9.

Hollomotz, A. (2011). Learning difficulties and sexual vulnerability: a social approach. London: (Jessica Kingsley.

Home Office. (2016). Hate Crime, England and Wales, 2015/16. London: HMSO.

Home Office (2015). Statutory guidance framework: controlling or coercive behaviour in an intimate or family relationship. London: Home Office.

Hughes, B. \& Paterson, K. (1997). The social model of disability and the disappearing body: Towards a sociology of impairment. Disability \& Society, 12(3), pp. 325-340.

Karr, V. L. (2011). Life of Quality: Informing the UN Convention on the Rights of Persons With Disabilities. J of Disability Policy Studies, 22(2), 67-82

Keywood, K. (2000). My Body and Other Stories: Anorexia Nervosa and the Legal Politics of Embodiment. Social \& Legal Studies, 9(4), 495-513. 
Keywood, K. (2002) Disabling sex: some legal thinking about sterilisation, learning disability and embodiment. In A. Morris and S.Nott (Eds). Well women: the gendered nature of healthcare provision (pp. 21-39). Aldershot: Ashgate.

Keywood, K. (2011) Safeguarding Reproductive Health: The inherent jurisdiction, contraception, and mental incapacity. Medical Law Review, 19(2), 326-333.

Knight, A. (2014). Disability as Vulnerability: Redistributing Precariousness in Democratic Ways . Journal of Politics, 76 (1), 15-26

Luton Borough Council (2011). The Serious Case Review into the Care and Treatment of Adult A . Luton: Luton Borough Council.

https://www.luton.gov.uk/Health_and_social_care/Lists/LutonDocuments/PDF/Community\% 20Care/Protecting\%20Vulnerable\%20Adults/Adult\%20A\%20Exec\%20Summary.pdf

Leach Scully, J. (2014). Disability and vulnerability: on bodies, dependency and power. In C. Mackenzie, W. Rogers \& S. Dodds (Eds.), Vulnerability: New Essays in Ethics and Feminist Philosophy (pp. 204-221). New York: OUP.

Lindsey, J. (2016). Developing vulnerability: a situational response to the abuse of women with mental disabilities. Feminist Legal Studies, 25, 295-314.

McKenzie, J. A. \& MacLeod, C.I. (2012). Rights discourses in relation to education of people with intellectual disability: towards an ethics of care that enables participation. Disability \& Society, 27(1), pp. 15-29.

MacKenzie, C., Rogers, W. \& Dodds,S (Eds). ( 2014). Vulnerability: new essays in ethics and Feminist philosophy. USA: Oxford University Press.

MacKenzie, C. (2014). The importance of relational autonomy and capabilities for an ethics of vulnerability. In C. MacKenzie, W. Rogers \& S. Dodds (Eds.), Vulnerability: new essays in ethics and Feminist philosophy (pp. 33-59). USA: Oxford University Press.

ten Have, H. (2016). Vulnerability: challenging bioethics. Abingdon: Routledge.

Mazars. (2015). Independent review of deaths of people with a Learning Disability or Mental Health problem in contact with Southern Health NHS Foundation Trust April 2011 to March 2015. London: Mazars.

Melling, J., Forsythe, B. \& Adair, R. (1999). Families, communities and the legal regulation of lunacy in Victorian England: Assessments of crime, violence and welfare in admissions to the Devon Asylum, 1845-1914). In P. Bartlett and D. Wright (Eds.), Outside the walls of the asylum: the history of care in the community 1750-2000 (pp.153-180). London: The Athlone Press.

Mladenov, T., Owens, J., Cribb, A. (2015), Personalisation in disability services and healthcare: A critical comparative analysis. Critical Social Policy, 35(3), pp. 307-326. 
Munby, J. (2014). Protecting the rights of vulnerable and incapacitous adults - the role of the courts: an example of judicial law making. Child \& Family Law Quarterly, 26(1) 64-77.

NHS Digital, (2016). Personal Social Services Adult Social Care Survey. London: NHS Digital.

Naffine. N. (1997). The body bag. In N. Naffine \& R. Owen (Eds.), Sexing the Subject of Law (pp 79-94). London: Sweet \& Maxwell.

National Health Service. (2016). Safeguarding Adults: Annual Report (England 2015-16) Experimental Statistics. http://www.content.digital.nhs.uk/catalogue/PUB21917.

Norrie, C., Manthorpe, J., Cartwright, C., Rayat, P. (2016). The feasibility of introducing an adult safeguarding measure for inclusion in the Adult Social Care Outcomes Framework (ASCOF): findings from a pilot study. BMC Health Services Research, 16 (209), 1-13.

Oakley, L.R., Fenge, L., Bass, S. \& Humphreys, J. (2016). Exploring the complexities of understanding vulnerability and adult safeguarding within Christian faith organisations. Journal of Adult Protection, 18(3), 172-183.

Oliver, M. \& Barnes, C. ( 2012). The new politics of disablement. New York: Palgrave.

Penson, W. J. (2015). Unsettling impairment: mental health and the social model of disability (pp 57-66 ) in H. Spandler; J. Anderson \& B. Sapey (Eds). Madness, Distress and the Politics of Disablement. Bristol: Policy Press

Perroni, L., \& Timmer, A. (2013). Vulnerable Groups: the Promise of an Emergent Concept in European Human Rights Convention Law. International Journal of Constitutional Law, $11,1056-1085$.

Pring, J. (2011). Longcare Survivors: the biography of a care scandal. York: Disability News Service.

Pritchard-Jones, L. (2017). “ This Man with Dementia"-'Othering' the Person with Dementia in the Court of Protection. Medical Law Review. https://doi.org/10.1093/medlaw/fww022.,

Ryan, S. (2016). Presentation for Taking Stock, Manchester $21^{\text {st }}$ October 2016. https://www.youtube.com/watch?v=KGUeFzNegfg

Ruck-Keene, A. (2014). A true tangle: capacity, influence and the inherent jurisdiction. http://www.mentalcapacitylawandpolicy.org.uk/a-true-tangle-capacity-influence-and-theinherent-jurisdiction/.

Sherwood-Johnson, F. (2013). Constructions of 'vulnerability' in comparative perspective: Scottish protection policies and the trouble with 'adults at risk'. Disability \& Society, 28(7), 908-921.

Shildrick, M. (2002). Embodying the monster: encounters with the vulnerable self. London: SAGE. 
Spandler, H. (2004). Friend or foe? towards a critical assessment of direct payments. Critical Social Policy, 24(2), 187-209.

South Central NHS Strategic Health Authority (2006). Report of the Independent Inquiry into the care and treatment of Mr E: board paper HA06/025. http://hundredfamilies.org/wp/wpcontent/uploads/2013/12/ROBERT_BROWNING_AUG04.pdf.

Southern Health NHS Trust. Trust statement regarding Connor Sparrowhawk's death, 2016. Southern Health NHS Trust: Southampton.

Suzuki, A. (1999). Enclosing and disclosing lunatics within the family walls: domestic psychiatric regime and the public sphere in early nineteenth-century England. In P. Bartlett and D. Wright (Eds.), Outside the walls of the asylum: the history of care in the community 1750-2000 (pp.153-180). London: The Athlone Press.

Welsh Assembly. (2000). In safe hands: implementing adult protection procedures in Wales. Cardiff: Welsh Assembly.

\section{Cases}

A Healthcare NHS Trust $v P$ and $Q$ [2015] [2015] EWCOP 15

A Local Authority v DL [2011] EWHC 1022 (Fam)

A Local Authority v Ma, Na, Sa (by her children's guardian LJ) 2005] EWHC 2942 (Fam)

A Local Authority v Mrs A and Mr A [2010] EWHC 1549 (Fam)

Amina Al-Jeffery v Mohammed Al-Jefferey [2016] EWHC 2151 (Fam)

Derbyshire County Council v AC [2014] EWCOP 38

Keenan v United Kingdom [2001] ECHR 242

$L B L v R Y J \& V J[2010]$ EWHC 2665

London Borough of Ealing v KS \& Ors [2008] EWHC 636 (Fam)

$N C C v B$ and $T B$ [2014] EWCOP 14

O'Keeffe v Ireland (2014) 59 EHRR 15.

PC v York 2013 [2013] EWCA Civ 478 
$\operatorname{Re} F$ [2000] 1 FLR 192

Re FD (Inherent Jurisdiction: Power of Arrest) [2016] EWHC 2358 (Fam)

Re G (An Adult) (Mental Capacity: Court's Jurisdiction)[2004] EWHC 2222 (Fam)

Re SO [2015] EWHC 935 (Fam)

$\operatorname{Re} Z$ [2004] EWHC 2817 (Fam) 